\title{
THE RELATIONSHIP OF THE RENAL EXCRETION OF ADRENAL CORTICOIDS TO VARIATIONS IN RENAL HEMODYNAMICS ${ }^{1}$
}

\author{
By LEON J. MARKS ${ }^{2}$ and ALEXANDER LEAF 3 with THE techNical assistance of \\ KIRSTEN VAN LOON
(From the Research Laboratory, Boston Veterans Administration Hospital and the Children's Medical Service and the Department of Medicine, Massachusetts General Hospital, and the Departments of Pediatrics and Medicine, Harvard Medical School)

(Submitted for publication February 18, 1953; accepted May 15, 1953)

\section{INTRODUCTION}

Measurements of urinary adrenal corticoid excretions have been widely used for the evaluation of adrenal hormone production and degradation. The possibility that renal dysfunction may alter the urinary excretion of these substances is generally ignored.

The present study was done in experimental animals in which controlled acute unilateral alterations of renal hemodynamics were produced during periods of hormone administration. The results indicate that alterations in renal hemodynamics are associated with definite changes in urinary corticoid excretion.

\section{METHODS}

Studies were done on four trained unanesthetized female dogs surgically prepared by Dr. Walter S. Kerr, Jr. These animals had their bladder trigone explanted to the anterior abdominal wall so that urine could be collected separately from each kidney. The right kidney was explanted and a skin cuff was placed around the right renal artery so that by compression of this artery the glomerular filtration rate could be unilaterally altered. The opposite kidney served as the control in these studies.

Three of the animals had no more than 10 per cent difference in creatinine and inulin clearances of the two kidneys prior to compression of the exposed renal artery. By means of varying degrees of compression of the exposed renal artery, various gradations of reduction in filtration rate were obtained unilaterally. The other animal showed a persistent decrease of approximately 50 per cent in creatinine and inulin clearances from the explanted kidney. This latter animal later had approximately 40 per cent of the control left kidney removed

1 Supported in part by a Grant-in-Aid from the American Heart Association and the Worcester District Chapter of the Massachusetts Heart Association.

2 Milton Research Fellow in Pediatrics, Harvard Medical School, 1951-1952. Present address: Staff Physician, Boston Veterans Administration Hospital, Boston, Mass.

3 Howard Hughes Fellow in Medicine. surgically and was restudied three weeks post-operatively.

In these studies, endogenous creatinine clearances were used as the measure of glomerular filtration rate. Urine creatinine was analyzed by the method of Bonsnes and Taussky (1) and serum creatinine by the method of Hare and Hare (2). It has been shown that the clearance of true or exogenous creatinine is identical with the inulin clearance in the dog (3). As the method used for serum creatinine chromogen has been shown to yield values equal to true creatinine (4) it was felt that the endogenous creatinine clearances represented a measure of glomerular filtration rate in these experiments. Clearances on different days of inulin and exogenous creatinine in the same animals gave values comparable to those obtained by endogenous creatinine clearances in this study.

The biologically active adrenal corticoids in the urine were measured quantitively by the Speir's mouse eosinophile bio-assay (5). Adrenalectomized $\mathrm{BBF}_{1}$ mice were injected subcutaneously with 20 gamma of epinephrine and four hours later eosinophil counts were performed. Mice with eosinophil counts lower than 100 per cubic millimeter of whole blood were discarded. To assay urine quantitatively a standard dose-response curve was prepared using cortisone dissolved in 10 per cent ethanol. The sensitivity of this assay was found to be between 0.5 to 6 gamma of cortisone, in good agreement with Speir's results (5). Either 0.5 or $1.0 \mathrm{cc}$. of urine was injected per mouse. Four to eight mice were used per urine specimen. The urine was used either immediately or promptly frozen and used within one week of collection. The occurrence of toxic reactions was rare. The results of these urinary assays are expressed as corticoid excretion equivalent to the response obtained with a known amount of cortisone.

Normal dogs' urine consistently failed to show detectable amounts of biologically active adrenal hormones by this method. In order to obtain a positive urinary assay, it was found necessary either to stimulate adrenal activity with adrenocorticotrophic hormone (ACTH) or administer doses of 17-hydroxy, 11-dehydrocorticosterone (Compound E) or 17-hydroxycorticosterone (Compound F).

In addition to the bioassay 17, 21-dihydroxy-20ketosteroids were measured chemically on butanol extracts of urine acidified with sulfuric acid to $\mathrm{pH}$ 1.0. The butanol extracts were washed with $0.1 \mathrm{~N}$ sodium hydroxide, $0.01 \mathrm{~N}$ sulfuric acid and dried with anhydrous 
TABLE I

The effects of unilateral renal artery compression on the urinary excretion of creatinine and biologically active corticoids during the intravenous administration of $A C T H$

\begin{tabular}{|c|c|c|c|c|c|c|c|c|c|}
\hline Period & $\begin{array}{c}\text { Time } \\
\text { in } \\
\text { hours }\end{array}$ & Kidney & $\begin{array}{l}\text { Urine } \\
\text { volume } \\
\text { cc. per } \\
\text { period }\end{array}$ & $\begin{array}{l}\text { Creatinine } \\
\text { conc. } \\
\text { mgs./ce. }\end{array}$ & $\begin{array}{l}\text { Corticoid } \\
\text { conc. } \\
\gamma / c c .\end{array}$ & $\begin{array}{l}\text { Total } \\
\text { creatinine } \\
\text { excretion } \\
\text { mgs. per } \\
\text { period }\end{array}$ & $\begin{array}{c}\text { Total } \\
\text { corticoid } \\
\text { excretion } \\
\gamma \text { per } \\
\text { period }\end{array}$ & $\begin{array}{l}\text { Ratio } \\
\text { creatinine } \\
\text { excretion } \\
\text { R/L }\end{array}$ & $\begin{array}{c}\text { Ratio } \\
\text { corticoid } \\
\text { excretion } \\
\text { R/L }\end{array}$ \\
\hline
\end{tabular}

0 ACTH 40 mgs. I.V. started and sustained throughout experiment

Before clamping

\begin{tabular}{|c|c|c|c|c|c|c|c|c|}
\hline 4-5 (60 min.) & $\begin{array}{l}\mathrm{R} \\
\mathrm{L}\end{array}$ & $\begin{array}{l}5.3 \\
7.4\end{array}$ & $\begin{array}{l}1.95 \\
1.69\end{array}$ & $\begin{array}{l}4 \\
4\end{array}$ & $\begin{array}{l}10.3 \\
12.5\end{array}$ & $\begin{array}{l}21.2 \\
29.6\end{array}$ & 0.83 & 0.72 \\
\hline \multicolumn{9}{|c|}{ Slight compression right renal artery } \\
\hline II $\quad 5\}-6 \frac{1}{2}(60 \mathrm{~min})$. & $\begin{array}{l}\mathrm{R} \\
\mathrm{L}\end{array}$ & $\begin{array}{l}5.5 \\
7.4\end{array}$ & $\begin{array}{l}1.33 \\
1.63\end{array}$ & $\begin{array}{l}2 \\
4\end{array}$ & $\begin{array}{r}7.3 \\
12.0\end{array}$ & $\begin{array}{l}11 \\
29.6\end{array}$ & 0.61 & 0.37 \\
\hline \multicolumn{9}{|c|}{ urther compression right renal artery } \\
\hline III $\left.\quad 7-8 \frac{1}{(75} \mathrm{min}.\right)$ & $\begin{array}{l}\mathrm{R} \\
\mathrm{L}\end{array}$ & $\begin{array}{r}5.0 \\
10.1\end{array}$ & $\begin{array}{l}0.86 \\
1.53\end{array}$ & $\begin{array}{l}0.5 \\
5\end{array}$ & $\begin{array}{c}4.33 \\
15.5\end{array}$ & $\begin{array}{r}2.5 \\
50.5\end{array}$ & 0.28 & 0.05 \\
\hline
\end{tabular}

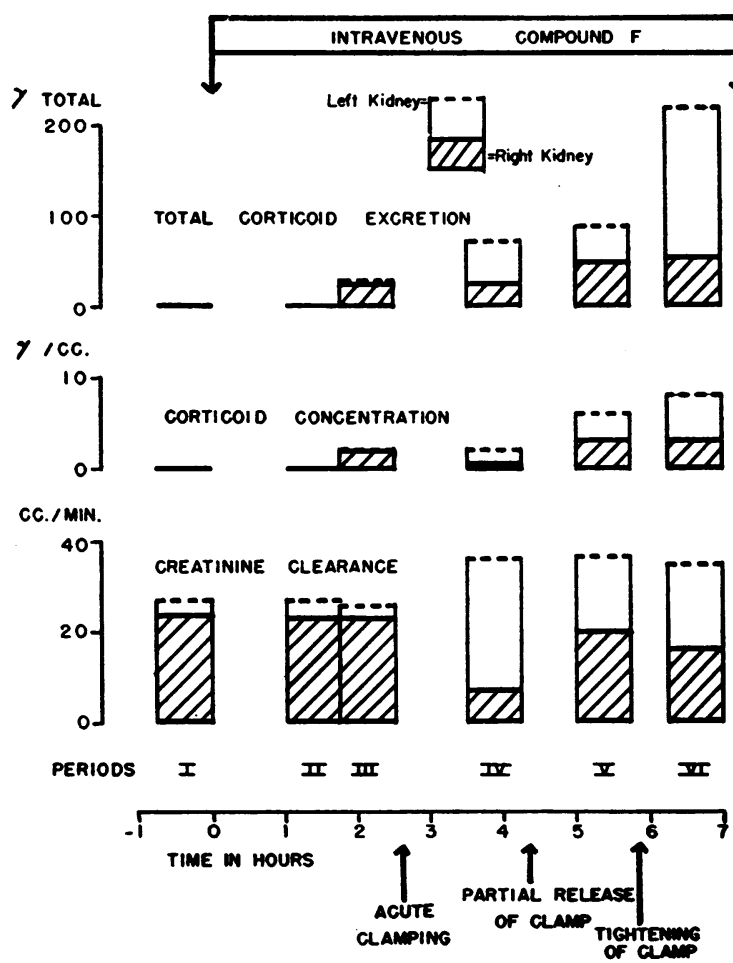

Fig. 1. The Effects of Right Renal Artery Compression on the Creatinine Clearance, Urinary Corticom Concentration, and Urinary Corticom ExCRETION DURING the Intravenous Administration of Compound F

Between periods $\mathrm{V}$ and VI the rate of infusion of Compound $F$ was increased. Corticoid here refers to biologically active corticoid (see text). By total corticoid excretion is meant the total urinary excretion of biologically active corticoids per period. The periods were from 30 to 45 minutes duration. sodium sulfate. The Porter-Silber reaction was applied directly to the butanol solution $(6,7)$. Solutions containing 5 and 10 micrograms per milliliter of 17hydroxycorticosterone dissolved in butanol were used as standards. The chemical corticoids were not measured in the same experiments as the biologically active corticoids.

Methods of administration used were as follows:

(a) After an initial priming dose intramuscularly of $40 \mathrm{mgs}$. of ACTH, an intravenous infusion of $500 \mathrm{cc}$. of 5 per cent dextrose in water containing 40 mgs. of ACTH was administered over an eight hour period. Urine collections were begun four hours after starting the intravenous infusion.

(b) 150 to $250 \mathrm{mgs}$. of cortisone acetate were administered by means of a stomach tube and urine collections were begun 90 to 120 minutes later.

(c) 50 mgs. of hydrocortisone (Compound F) ${ }^{4}$ dissolved in $250 \mathrm{cc}$. of 2 per cent ethanol and 5 per cent dextrose were given intravenously over a six hour period and urine collections were started immediately.

\section{RESULTS}

Protocols of two representative experiments are shown in Table I and Figure 1. In the experiment recorded in Table $\mathrm{I}$, positive urinary bioassays were obtained by adrenal stimulation with a continuous intravenous infusion of ACTH. The effects of unilateral compression of the right renal artery on urine volumes, creatinine and corticoid excretions in three separate periods of 60 to 75 minutes duration are shown. As the right renal

4 This hormone was generously supplied by Merck Co., Rahway, New Jersey. 
artery was progressively compressed, both creatinine and corticoid excretions diminished. In this experiment, the fall in corticoid excretion is largely due to a decrease in concentration of corticoid rather than to a change in urine volume (urine volumes on right were $5.3,5.5,5.0 \mathrm{cc}$. with associated corticoid excretions of 21,11 , and 2.5 gamma, respectively). Comparison of the ratios of creatinine excretion and of corticoid excretion by both kidneys revealed that corticoid excretion was more strikingly reduced by compression than was creatinine excretion.

Figure 1 illustrates the effects of the continuous intravenous infusion of Compound $F$ and varying degrees of right renal artery compression on the creatinine clearances, urinary biologically active corticoid concentrations, and total biologically active corticoid excretions in six separate periods of 30 to 45 minutes duration. The interruptions between periods of urine collections were made in an attempt to flush out urine formed during preceding procedures from renal dead space. In period III, before renal artery compression, urinary corticoid concentrations and excretions were equal at a time when the creatinine clearances were approximately the same. The drop in creatinine clearances due to partial compression of the right renal artery was associated with decreased corticoid concentrations and total corticoid excretion from the right as compared to the left kidney. In this experiment, decreased corticoid excretion in the urine from the right kidney was related to both decreased urine volume and decreased corticoid concentration.

There is a time lag of one to two hours after beginning Compound $\mathrm{F}$ administration before hormone excretion became measurable. Change of hormone excretion with variation in creatinine clearance is prompt. The marked increase in corticoid excretion in the last period may be related to an increase in the rate of infusion at this time. A slight increase in the control creatinine clearances was noted three and one-half hours after starting the Compound $\mathrm{F}$ infusion and one

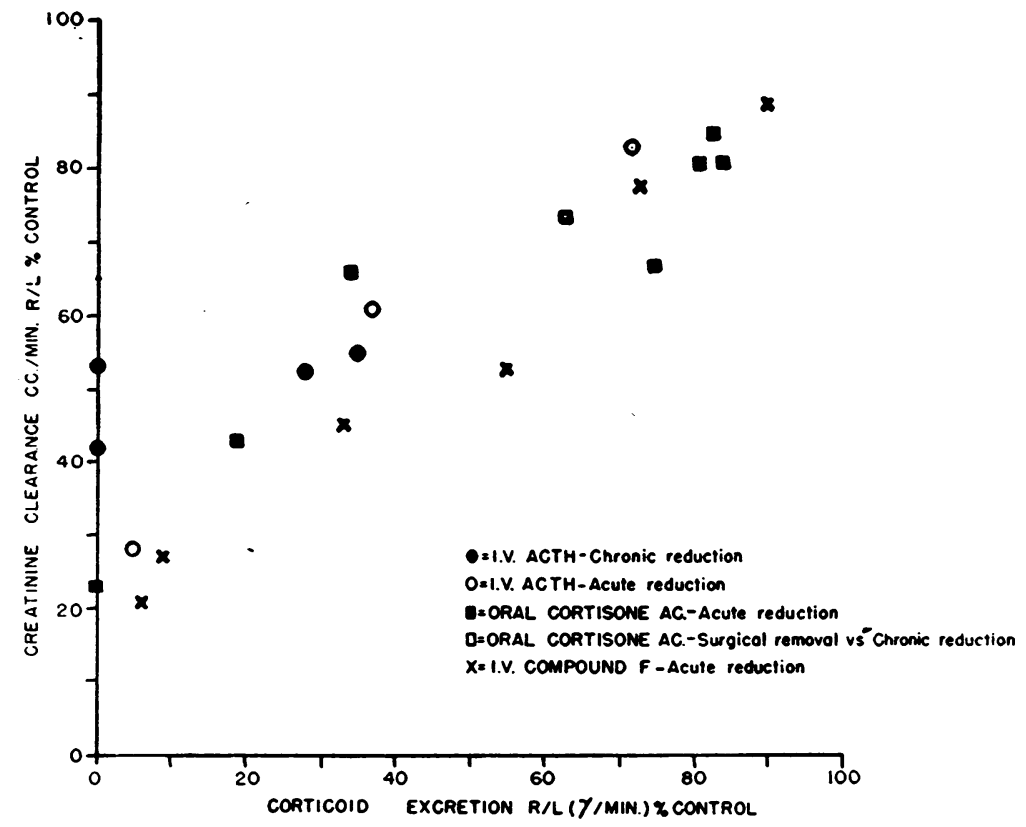

Fig. 2. A Summary of the Results of Twenty-one Separate Clearance Periods Showing the Relationship of Biologically-Active Corticoid Excretion to Creatinine Clearance by the Right Kidney Plotted as Per Cent of the Corresponding Excretion by the Control Left Kidney

Chronic reduction refers to the persistent reduction in creatinine clearance in one animal used. Surgical removal vs. chronic reduction refers to use of this animal after extirpation of 40 per cent of the control kidney (see text). The periods were 30 to 75 minutes each. 
hour after partial compression of the contralateral renal artery.

Figure 2 is a summary of the results of twentyone experimental periods, including forty-two urinary bio-assays. There is a positive correlation between creatinine clearance and biologically active corticoid excretion. In no instance did biologically active corticoid excretion from the right kidney exceed that from the control kidney on the left. The three points on the extreme left representing a zero corticoid excretion may simply be a reflection of the lower limit of sensitivity of the bio-assay method, and therefore cannot be further interpreted. However, a line which best fits the observed data would intersect the ordinate significantly above zero. This suggests that at very low rates of glomerular filtration the urinary excretion of biologically active adrenal corticoids decreases sharply.

Figure 3 summarizes the results of 20 additional experimental periods in which the chemical corticoid excretions were measured. A linear relation-

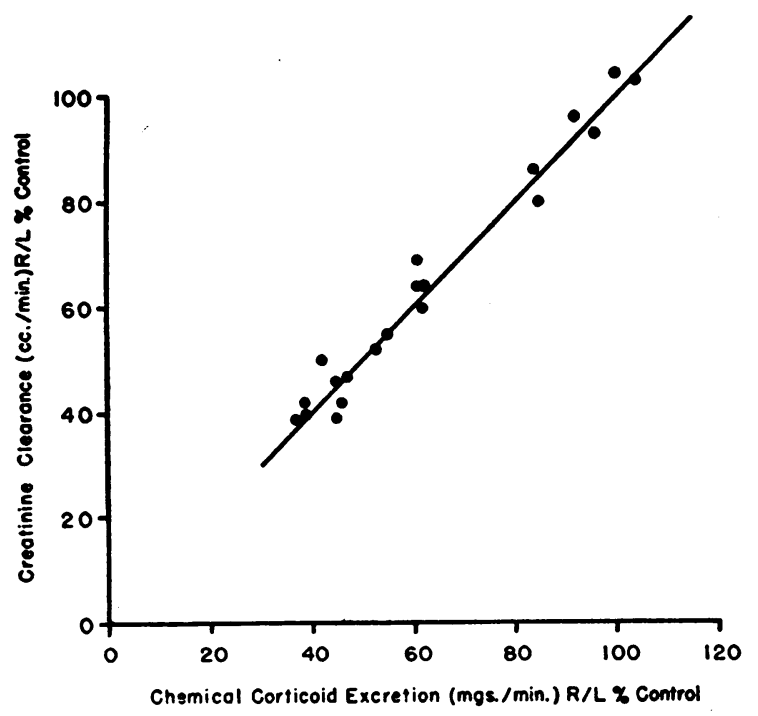

Fig. 3. A Summary of the Results of Twenty Separate Clearance Periods Showing the Reiationship of Chemical Corticoid Excretion to Creatinine Clearance by the Right Kidney Plotted as Per Cent of the Corresponding Excretion by the Control Left KIDNEY

Cortisone acetate was administered by stomach tube to obtain the observed levels of hormone excretion in all these periods. The periods were 20 to 60 minutes each. The line drawn arbitrarily through the points has a slope of 1.0 . ship between creatinine clearance and chemical corticoid excretion is apparent. A line which best fits the observed data would pass through zero.

\section{DISCUSSION}

By compressing one renal artery and comparing the excretion of hormone from that kidney with that of the opposite control kidney, it was possible to assess the relative effects of decreased filtration rate or blood flow on the excretion of biologically active corticoids without knowledge of the blood levels of these hormones. It has, however, been recently shown that following the administration of ACTH or cortisone intravenously or cortisone acetate orally, the blood level of 17-hydroxycorticosteroids rises two to ten times above its original level $(8,9,10)$ and with the known values for renal blood flow, the minute quantities of hormone excreted in these experiments must represent only a small fraction of the hormone perfusing kidneys. This is in agreement with the absence of a significant arterial-venous concentration difference of 17-hydroxycorticosteroids in the dog kidney noted by Nelson (9), and the low estimate of renal clearance of formaldehydogenic corticosteroids made by Corcoran and Page (11).

From the manner in which these experiments were conducted, it is impossible to state whether the observed acute changes in hormone excretion were due to changes in filtration rate or to the simultaneous alterations occurring in renal blood flow, or tubular function. Goldman and Bassett (12) noted that the excretion of neutral lipidsoluble reducing steroids was proportional to the excretion of creatinine in their study of patients with cirrhosis and congestive heart failure and suggested that the excretion of corticosteroids may be proportional to the filtration rate. As no information is available at present regarding the filtrability of adrenal corticoids through the glomerular membrane, it is not possible to decide whether the changes in hormone excretion were due to changes in the amount filtered, or in tubular reabsorption or tubular secretion or hormone.

The disappearance of biologically active corticoids from the urine at low levels of glomerular filtration rate in contrast to the continued excretion of chemical corticoids may simply be an artifact arising from the limit of sensitivity of the 
bio-assay used. Another cause for this apparent difference may be that the high rates of chemical corticoid excretion in these experiments were masking an increment of tubular reabsorption of chemical corticoids. The possibility exists, however, that at a given filtration rate proportionately more of the filtered corticoids which are biologically active are reabsorbed by the renal tubules than is the case with the majority of corticoids measured chemically.

\section{SUMMARY}

The effects of acute variations in glomerular filtration rate on the renal excretion of biologically active adrenal corticoids and chemical corticoids were evaluated in dogs. Acute alterations in renal hemodynamics were produced by unilateral compression of one renal artery during periods of adrenal stimulation or administration of adrenal corticoids. With reduction of glomerular filtration rate there occurred a decrease in excretion of both biologically-active adrenal corticoids and chemical corticoids.

\section{ACKNOWLEDGMENTS}

The authors wish to express their gratitude to Drs. A. M. Butler and N. B. Talbot who generously made available the facilities of their laboratories for this study. They also wish to thank Drs. Walter Bauer and M. B. Strauss for their criticism of this study.

\section{REFERENCES}

1. Bonsnes, R. W., and Taussky, H. H., On the colorimetric determination of creatinine by the Jaffe reaction. J. Biol. Chem., 1945, 158, 581.
2. Hare, R. S., and Hare, K., Determination of creatinine in blood and urine. Federation Proc., 1949, 8, 68.

3. Shannon, J. A., The excretion of inulin by the dog. Am. J. Physiol., 1935, 112, 405.

4. Miller, Z., and Miller, B. F., Specific determination of serum creatinine. Proc. Soc. Exper. Biol. \& Med., 1951, 78, 471.

5. Speirs, R. S., and Meyer, R. K., A method of assaying adrenal cortical hormones based on a decrease in the circulating eosinophile cells of adrenalectomized mice. Endocrinology, 1951, 48, 316.

6. Porter, C. C., and Silber, R. H., A quantitative color reaction for cortisone and related 17, 21-dihydroxy20-ketosteroids. J. Biol. Chem., 1950, 185, 201.

7. Reddy, W. J., Jenkins, D., and Thorn, G. W., Estimation of 17 -hydroxycorticoids in urine. Metabolism, 1952, 1, 511.

8. Nelson, D. H., and Samuels, L. T., A method for the determination of 17-hydroxycorticosteroids in blood: 17-hydroxycorticosterone in the peripheral circulation. J. Clin. Endocrinol., 1952, 12, 519.

9. Nelson, D. H., Determination of adrenal cortical steroids in blood. Conference on Adrenal Cortex. Josiah Macy, Jr. Foundation, 1951, 3, 89.

10. Nelson, D. H., Sandberg, A. A., Palmer, J. G., and Tyler, F. H., Blood levels of 17-hydroxycorticosteroids following the administration of adrenal steroids and their relation to levels of circulating leukocytes. J. Clin. Invest., 1952, 31, 843.

11. Corcoran, A. C., and Page, I. H., Methods for the chemical determination of corticosteroids in urine and plasma. J. Lab. \& Clin. Med., 1948, 33, 1326.

12. Goldman, R., and Bassett, S. H., Diurnal variation in the urinary excretion of neutral lipid-soluble reducing steroids in congestive cardiac failure and cirrhosis of the liver with ascites. J. Clin. Invest., 1952, 31, 253. 